\section{Immunophenotypic Evaluation of Skin in Psoriasis: A Case Control Study}

\section{Prafulla Kumar Sharma ${ }^{1}$, Neha Meena ${ }^{1 *}$ and Minakshi Bhardwaj $^{2}$}

${ }^{1}$ Department of Dermatology, STD and Leprosy, PGIMER, Dr. Ram Manohar Lohia Hospital, Baba Kharak Singh Marg, New Delhi, India ${ }^{2}$ Department of Pathology, PGIMER, Dr. Ram Manohar Lohia Hospital, Baba Kharak Singh Marg, New Delhi India

\begin{abstract}
Background

Pathogenesis of psoriasis is complex. Latest evidences suggest the role of T-lymphocytes (CD4+, CD8+, and CD45RO+ memory $T$ cells), Langerhans cells (CD1a+) and VEGF in the altered keratinocytes kinetics.

\section{Aims and objectives}

To evaluate the extent of infiltration of T-lymphocytes (CD4+, CD8+, CD45RO+), Langerhans cells (CD1a+) and VEGF in lesional and non lesional skin in psoriatic patients and healthy controls.

\section{Materials and methods}

Twenty-five untreated psoriasis cases were taken up for study. Five millimeter biopsies of the patient's skin were taken from the newest Psoriasis Lesion (PL) and the farthest non-lesional skin (PN). They were stained with H\&E (Hematoxylin and Eosin stain) and with monoclonal antibody against CD4+, CD8+, CD45RO+ T cells, CD1a+ and VEGF. Skin biopsies of 5 healthy controls were also subjected to the same stain.

Results

On hematoxylin and eosin staining, the degree of cellular infiltrate was more in PL dermis than PL epidermis, while similar degree of cellular infiltrate was found in PN epidermis and dermis. Dermal vascular proliferation was also higher in PL than in PN. On immunohistochemical evaluation, epidermal infiltrate of CD4+ $T$ cells, CD8+ T cells and CD1a+ cells were more abundant in PL than in PN. Also, VEGF was more expressed in the epidermis of PL than in $\mathrm{PN}$. However, CD45RO+ T cells were more in the dermis of PL than in PN. When comparing PL and PN with healthy controls, there was increased infiltration of all markers when compared to controls.
\end{abstract}

${ }^{*}$ Corresponding author: Neha Meena, Department of Dermatology, STD and Leprosy, PGIMER, Dr. Ram Manohar Lohia Hospital, Baba Kharak Singh Marg New Delhi-110001, India, Tel: +91 9953943781; E-mail: neha.doc.dr@gmail.com

Citation: Meena N, Sharma PK, Bhardwaj M (2015) Immunophenotypic Evaluation of Skin in Psoriasis: A Case Control Study. J Clin Dermatol Ther 2: 007.

Received: January 2, 2015; Accepted: February 5, 2015; Published: February 19, 2015

\begin{abstract}
Conclusion
The inflammatory process in psoriasis involves the whole skin of the patient, but is more pronounced in the damaged skin.

Keywords: Immunohistochemistry; Immunophenotypic; Psoriasis; Vascular Endothelial Growth Factor; CD4+ T Cells; CD8+ T Cells; CD45RO+ T Cells; CD1a+ Cells
\end{abstract}

\section{Introduction}

Psoriasis is a chronic inflammatory disorder triggered by dysregulated immune response, genetic and environmental factors [1-5]. The pathophysiology of psoriasis is characterized by the complex interaction between epidermal keratinocytes, lymphocytes, neutrophils and dendritic cells in epidermis and dermis, and enhanced secretion of growth factors and cytokines that lead to an increase in the rate and number of proliferating keratinocytes in epidermis and dermal vascular changes [6-8]. Lately role of T-lymphocytes, mainly CD4+ cells [9,10], CD8+ cells [11], CD45RO+ memory T cells [12] and Langerhan's cells (CD1a+ cells) [13] has been suggested in the pathogenesis of psoriasis. Also, Vascular Endothelial Growth Factor (VEGF) is associated with the vascular changes in psoriasis [14]. Previous immunohistochemical studies focused on either $\mathrm{T}$ cells, dendritic cells or on vascular changes. The aim of the study was conducted to evaluate the degree of the involvement of CD4+ T cells, CD8+ T cells, CD45RO+ T cells, CD1a+ cells infiltrate and VEGF in the involved and uninvolved skin of patients suffering from psoriasis and to compare this situation with healthy controls.

\section{Materials and Methods}

This prospective study was conducted in the Department of Dermatology, STD and Leprosy at PGIMER, Dr. Ram Manohar Lohia Hospital, New Delhi, India in the years 2010-2012. It was approved by the Institutional Ethics committee (No.1/2010/PGIMER-RMLH/ EC/Vol.II/390). Twenty-five consecutive untreated cases of plaque psoriasis, diagnosed clinically on the basis of morphological appearance of lesions, positive grattage test and Auspitz sign were taken up for study after informed written consent. Patients of psoriasis already on treatment, pregnant women, rheumatoid factor positive and HIV positive patients were excluded. 5 healthy volunteers who gave their consent for skin biopsy were taken as control. Body Surface Area (BSA) and Psoriasis Area Severity Index (PASI) score were calculated. 2 skin biopsies were taken from each patient by 5 $\mathrm{mm}$ punch, one from the edge of newest lesion (PL) and another from the farthest uninvolved skin (PN). $5 \mathrm{~mm}$ punch skin biopsy was also taken from each of the 5 healthy Controls (C). The biopsies were subjected to Hematoxylin and Eosin (H\&E) and Immunohistochemical (IHC) stains for T cells (CD4+, CD8+, and CD45RO+), CD1a+ cells and VEGF. The degree of cellular infiltrate (on both $\mathrm{H} \& \mathrm{E}$ staining and IHC) in the epidermis and dermis was then graded as 0 (no cell), 1+ (few cells), 2+ (aggregates of few cells), 3+ (diffuse distribution of cells). VEGF staining in epidermis and dermis was graded as 0 (no staining), $1+$ (little staining), 2+ (aggregates of staining), 3+ (diffuse staining). The vascular changes in the dermis on $\mathrm{H} \& \mathrm{E}$ was graded as 0 (no endothelial cell change), $1+$ (a few vessels/ capillaries show endothelial cells swelling), 2+ (aggregates of dilated 


\begin{tabular}{|c|c|c|c|c|c|c|c|c|c|c|c|c|}
\hline \multirow{2}{*}{ Epidermis } & \multicolumn{4}{|c|}{ PL-Grade / no of cases (\%) } & \multicolumn{4}{|c|}{ PN-Grade / no of cases (\%) } & \multicolumn{4}{|c|}{ C-Grade / no of controls (\%) } \\
\hline & 0 & 1 & 2 & 3 & 0 & 1 & 2 & 3 & 0 & 1 & 2 & 3 \\
\hline CD4+ T Cells & $14(56.0 \%)$ & $11(44.0 \%)$ & 0 & 0 & $23(92.0 \%)$ & $2(8.0 \%)$ & 0 & 0 & $5(100.0 \%)$ & 0 & 0 & 0 \\
\hline CD8+ T Cells & $2(8.0 \%)$ & $18(72.0 \%)$ & $5(20.0 \%)$ & 0 & $7(28.0 \%)$ & $18(72.0 \%)$ & 0 & 0 & $5(100.0 \%)$ & 0 & 0 & 0 \\
\hline CD $45 \mathrm{RO}+\mathrm{T}$ Cells & $4(16.0 \%)$ & $19(76.0 \%)$ & $2(8.0 \%)$ & 0 & $13(52.0 \%)$ & $12(48.0 \%)$ & 0 & 0 & $5(100.0 \%)$ & 0 & 0 & 0 \\
\hline CD1a+ Cells & $2(8.0 \%)$ & $22(88.0 \%)$ & $1(4.0 \%)$ & 0 & $4(16.0 \%)$ & $17(68.0 \%)$ & $4(16.0 \%)$ & 0 & $4(80.0 \%)$ & $1(20.0 \%)$ & 0 & 0 \\
\hline \multicolumn{13}{|l|}{ Dermis } \\
\hline CD4+ T Cells & $10(40.0 \%)$ & $12(48.0 \%)$ & $3(12.0 \%)$ & 0 & $16(64.0 \%)$ & $9(36.0 \%)$ & 0 & 0 & $4(80.0 \%)$ & $1(20.0 \%)$ & 0 & 0 \\
\hline CD8+ T Cells & $15(60.0 \%)$ & $6(24.0 \%)$ & $4(16.0 \%)$ & 0 & $16(64.0 \%)$ & $9(36.0 \%)$ & 0 & 0 & $4(80.0 \%)$ & $1(20.0 \%)$ & 0 & 0 \\
\hline CD 45 RO+ T Cells & $2(8.0 \%)$ & $4(16.0 \%)$ & $12(48.0 \%)$ & $7(28.0 \%)$ & $1(4.0 \%)$ & $18(72.0 \%)$ & $6(24.0 \%)$ & 0 & $4(80.0 \%)$ & $1(20.0 \%)$ & 0 & 0 \\
\hline CD1a+ Cells & $19(76.0 \%)$ & $6(24.0 \%)$ & 0 & 0 & $18(72.0 \%)$ & $7(28.0 \%)$ & 0 & 0 & 5 & & & \\
\hline$(100.0 \%)$ & 0 & 0 & 0 & & & & & & & & & \\
\hline
\end{tabular}

Table 1: The cellular infiltrate and VEGF expression in non lesional $(\mathrm{PN})$ and lesional $(\mathrm{PL})$ skin in psoriasis cases and in skin of healthy Controls (C).

vessels/capillaries), 3+ (diffuse distribution of dilated vessels/capillaries).

The data was statistically analysed using Mann-Whitney test, Student's t-test (unpaired), and Pearson's coefficient of correlation by SPSS (20.0) software. Null hypothesis was tested and $p$-value $<0.05$ (2-tailed) was considered as significant.

\section{Results}

Out of 25 cases, 17 were (68.0\%) males and 8 (32.0\%) females. The male to female ratio was found to be 2.13:1. The mean age of presentation was $37.72 \pm 13.49$ years, with mean age of onset of psoriasis was $34.68 \pm 12.43$ years. The mean duration of disease was $3.06 \pm 5.41$ years, however in $14(56 \%)$ cases, the duration was less than 4 months. The mean PASI was $5.84 \pm 4.81$, while mean BSA was $11.51 \pm 7.66$.

The degree of lymphocytic infiltrate in PL dermis was higher than PL epidermis $(\mathrm{p}=0.006)$, while similar degree of infiltrate was found in both epidermis and dermis of PN $(p=1.000)$. The degree of lymphocytic infiltrate in PL epidermis was higher than PN epidermis $(\mathrm{p}=0.025)$, similarly higher degree of lymphocytic infiltrate was found in PL dermis as compared to PN dermis $(\mathrm{p}<0.001)$. Vascular proliferation was more in dermis of PL as compared to $\mathrm{n} P \mathrm{~N}(\mathrm{p}=0.002)$. Neither infiltrate nor vascular proliferation was noted in control on H\&E staining (Table 1).

On Immunohistochemical evaluation of CD4+ T cells (Figure 1), we found similar degree of CD4+ T cells infiltration in PL epidermis and dermis $(\mathrm{p}=0.147)$ while, $\mathrm{PN}$ dermis had more infiltrate of $\mathrm{CD} 4+\mathrm{T}$ cells than PN epidermis $(\mathrm{p}=0.018)$. PL epidermis was more infiltrated by CD4+ T cells as compared to PN epidermis $(\mathrm{p}=0.004)$. However, similar degree of infiltrate of CD4+ T cells was found in dermis of both PL and PN ( $\mathrm{p}=0.053)$. Although, higher grades of CD4+ T cells infiltration were observed in PN epidermis and dermis when compared with epidermis and dermis of controls, respectively but the degree of infiltrate was similar according to the Mann-Whitney test [(epidermis $\mathrm{p}=0.520$, dermis $\mathrm{p}=0.496$ ) table 1$]$.

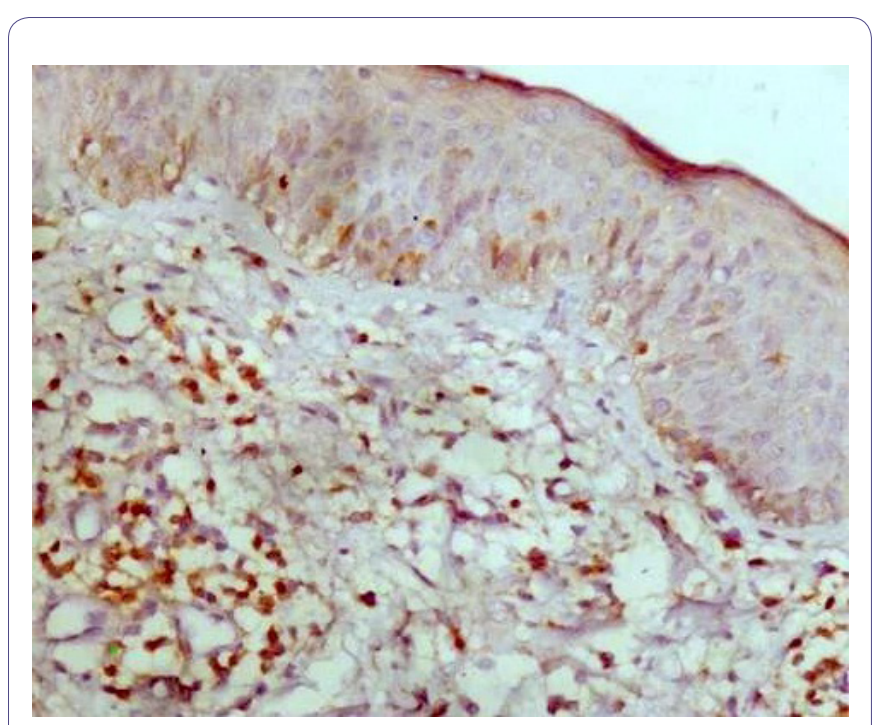

Figure 1: IHC staining (20x): CD4+ T cells in the dermis of damage skin.

The degree of CD8+ T cells (Figure 2) in the epidermis of PL and PN was higher than the PL dermis $(\mathrm{p}=0.003)$ and $\mathrm{PN}$ dermis $(\mathrm{p}=0.011)$ respectively. PL epidermis was infiltrated more by $\mathrm{CD} 8+\mathrm{T}$ cells than $\mathrm{PN}$ epidermis $(\mathrm{p}=0.008)$. However, we found similar degree of dermal infiltration of CD8 $+\mathrm{T}$ cells in both PL and PN ( $\mathrm{p}=0.490)$. When comparing $\mathrm{PN}$ and $\mathrm{C}$, we found that $\mathrm{PN}$ epidermis was more infiltrated of CD8+ T cells than $\mathrm{C}$ epidermis $(\mathrm{p}=0.003)$. Although, higher grades of dermal infiltration by $\mathrm{CD} 8+\mathrm{T}$ cells were noticed in PN than C, a similar degree of infiltration was found when applying the statistical analysis $(\mathrm{p}=0.496)$ (Table 1$)$.

The degree of infiltration of $\mathrm{CD} 45 \mathrm{RO}+\mathrm{T}$ cells (Figure 3) was superior in dermis of PL and PN than epidermis of PL $(\mathrm{p}<0.001)$ and PN $(p<0.001)$. The degree of CD45RO+ T cells infiltration was higher in both PL epidermis and dermis than PN epidermis $(\mathrm{p}=0.004)$ and $\mathrm{PN}$ dermis $(\mathrm{p}<0.001)$. Increased $\mathrm{CD} 45 \mathrm{RO}+\mathrm{T}$ cells infiltration was seen in PN (both in epidermis and dermis) than in controls $(\mathrm{p}=0.049$ and $\mathrm{p}=0.001$ for epidermis and dermis respectively) (Table 1 ). 


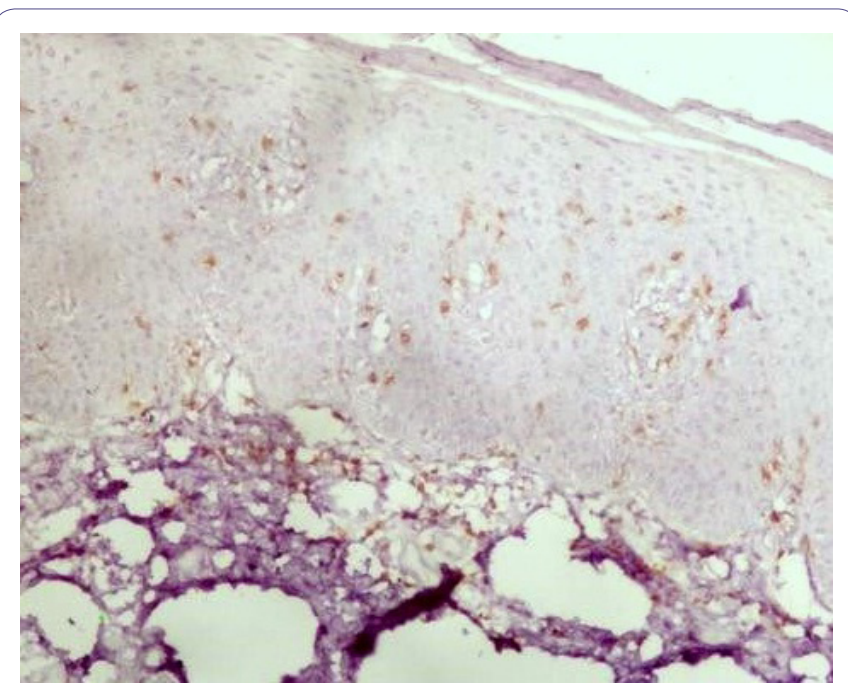

Figure 2: IHC staining (20x): CD8+ T cells in the epidermis of damage skin.

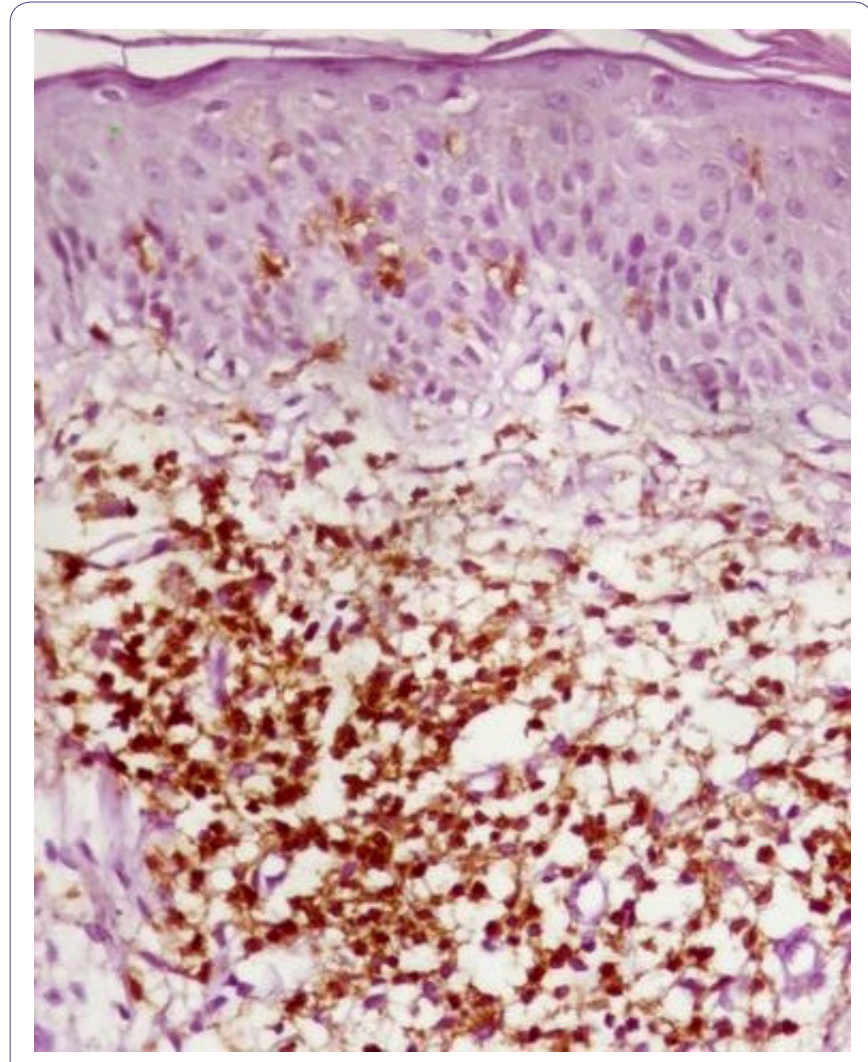

Figure 3: IHC staining (20x): CD45RO+ T cells in the dermis of damage skin.

CD1a+ cells infiltration (Figure 4) was of higher degree in epidermis in both PL and PN than in dermis in PL $(\mathrm{p}<0.001)$ and $\mathrm{PN}(\mathrm{p}<0.001)$ respectively. However, similar degree of infiltration of $\mathrm{CD} 1 \mathrm{a}+$ cells was found in PL epidermis and PN epidermis ( $\mathrm{p}=0.778)$. The degree of infiltrate of CDla+ cells was also similar in PL dermis and $\mathrm{PN}$ dermis $(\mathrm{p}=0.750)$. PN epidermis was more infiltrated by CD1a+ cells than C epidermis $(\mathrm{p}=0.007)$, while similar degree of infiltration by CDla + cells was found in PN dermis and C dermis $(\mathrm{p}=0.184)$ (Table 1$)$.

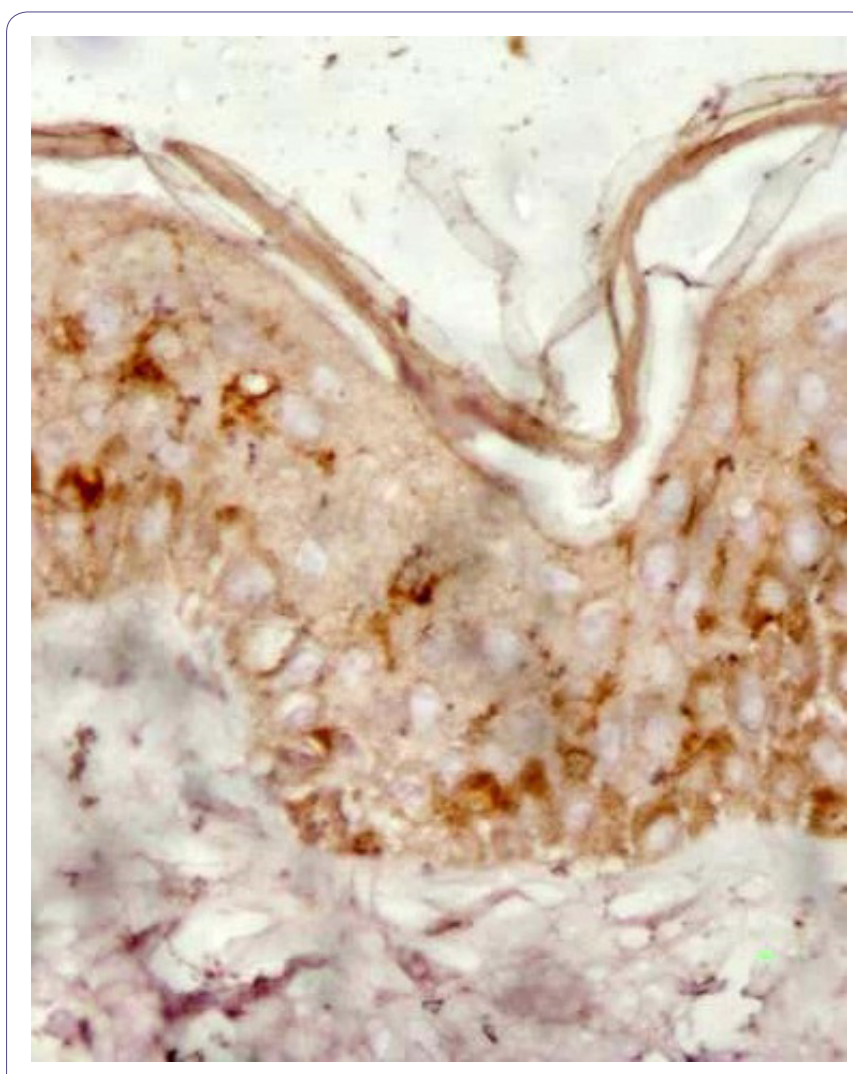

Figure 4: IHC staining (20x): CD1a+ cells epidermal infiltration-damage skin.

The degree of VEGF expression (Figure 5) on immunohistochemical evaluation was found to be higher in PL epidermis than PL dermis $(\mathrm{p}=0.036)$. Similarly, VEGF was more expressed in PN epidermis than $\mathrm{PN}$ dermis $(\mathrm{p}=0.046)$. The degree of VEGF expression was similar in epidermis of both PN and PL $(p=0.067)$. However, VEGF was expressed more in PL dermis than PN dermis $(\mathrm{p}<0.001)$. When comparing PN with controls, VEGF expression was found to be more in PN (both epidermis and dermis) than in controls ( $\mathrm{p}=0.009$ and $\mathrm{p}=0.001$ for epidermis and dermis respectively, table 1 ).

\section{Discussion}

Psoriasis is a chronic inflammatory disease mediated by complex interaction between cells and molecules of innate and adaptive immunity [1,6,7]. Keratinocytes are the target cells in the pathogenesis of psoriasis, as they recruit the $\mathrm{T}$ cell in the skin [8]. $\mathrm{T}$ cells are helpful in sustaining the disease process. According to a recent immunological pathway model of psoriasis, any triggering agent such as skin injury or antigen stimulates the innate immune response by activating keratinocytes. This lead to the activation of dendritic cells (myeloid and plasmacytoid) with antimicrobial peptides LL37, toll-like receptors TLR 7, 8 and 9. Activated myeloid cells in turn stimulate T cells which produce TNF- $\alpha$, IL-17, IFN- $\gamma$ and IL-22. These cytokines further stimulate keratinocytes, thus this vicious cycle continues $[1,6,7]$.

The H\&E and immunohistochemical stained biopsy slides were evaluated as per the grading illustrated in the materials and methods. Our results agree with previous published studies which found a similar finding as ours, of sparse superficial perivascular T-lymphocytic infiltrate in the dermis of early psoriatic plaque with normal epidermis. In this study, the degree of dermal infiltrate and 


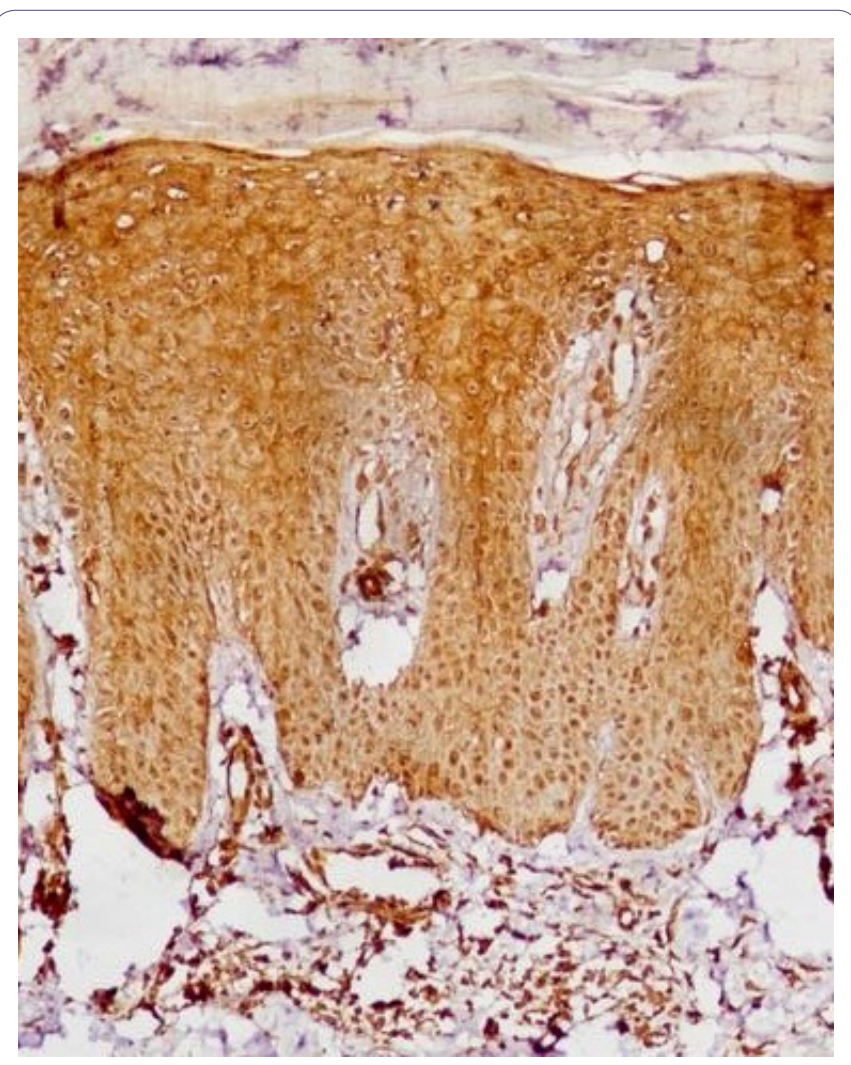

Figure 5: IHC (20x): Increased VEGF expression in epidermis and proliferation dermal capillaries in the damage skin.

dermal vessel proliferation were significantly higher in the dermis of affected skin [4-7]. The vascular proliferation was also detected in apparently healthy skin, though, with a lesser degree than in the damage skin.

Our finding of similar degree of CD4+ T cells infiltrate in lesional epidermis and dermis, but more in non lesional dermis was in agreement with previous studies [9-12]. We also found similar degree of CD4+ T cells infiltrate in dermis of both lesional and non lesional skin, while Keijsers et al., found higher dermal infiltrate in lesional skin and minimal or no infiltrate in distant non lesional skin [15]. Lesional and non lesional CD8 + T cells were infiltrated more in the epidermis of both lesional and non lesional skin as compared to the dermis. Previous studies also reported that epidermal T cells were chiefly CD8 $+\mathrm{T}$ cells $[4-7,11]$. We found increased infiltration of $\mathrm{CD} 45 \mathrm{RO}+\mathrm{T}$ cells in the dermis of both lesional and non-lesional skin of psoriasis as compared to the epidermis. Lesional skin show more infiltrate in both epidermis and dermis as compared to non lesional skin. However, Visser et al., reported more CD45RO+ T cells infiltrate in epidermis [11]. Activated CD8+ T cells and CD45RO+ T cells are early invading $\mathrm{T}$ cells in psoriatic lesions, thus indicates their role in evolution of psoriatic lesion from normal appearing skin of psoriasis patients $[11,12]$.

This study supports the previous findings that uninvolved skin in psoriasis and lesional skin show slightly increased numbers of $\mathrm{CD} 4+\mathrm{T}$ cells, $\mathrm{CD} 8+\mathrm{T}$ cells and $\mathrm{CD} 45 \mathrm{RO}+\mathrm{T}$ cells with a few CD1a+ dendritic cells as compared to skin of controls [9-13].

CD1a+ cells were concentrated more in the epidermis in both the lesional and non-lesional skin as compared to dermis. Further, the degree of CDla+ cells infiltrate was similar in epidermis of PN and PL, which is in contrast to the study by Komine et al., [13]. They noted that the density and the number of CDla+ cells were increased in the epidermis of the lesional skin as compared to the uninvolved skin [13]. Deguchi et al., showed that the number of CD1a-positive epidermal langerhans cells in psoriatic lesions was not significantly different from that of normal controls, while we found higher epidermal CD1a+ cells infiltrate in lesional and non lesional skin than in controls [16]. Other studies reported variable results $[17,18]$. Recent evidences suggest impaired migration of Langerhans cells in early onset psoriasis [19]. But its role in the pathogenesis is still unclear [1].

VEGF was expressed more in epidermis of both lesional and non lesional skin than in dermis. However, the degree of dermal VEGF expression was more in the lesional skin as compared to non lesional skin. Thus, the presence of significant vascular proliferation in psoriatic (lesional and non lesional) skin correlate with the intense positivity of VEGF in both epidermal and dermal areas as reported earlier [14,20,21]. This study also highlights the increased VEGF expression in non lesional skin not reported previously. VEGF had been shown to be over expressed in suprabasal keratinocytes and endothelial cells of the vessels of papillary dermis of psoriatic skin [20-23]. Epidermal VEGF production is required for the development of dermal angiogenesis and for autocrine regulation of epidermal hyperplasia [23-26].

\section{Limitation of the Study}

Because of the ethical issues and other laboratory constraints, only 5 healthy volunteer controls were taken in the study. Though we agree that the numbers should have been more. Similar studies with larger sample size and controls can be of great addition to know the pathogenesis of psoriasis.

\section{Conclusion}

Thus, the study demonstrates the involvement of the whole skin of a psoriasis patient but with different degree of involvement by various $\mathrm{T}$ cells (CD4+ T cells, CD8+ T cells, CD45RO+ T cells), CD1a and VEGF. The apparently uninvolved areas seem to be ready to react when the adequate stimuli appears. These stimuli may affect the whole skin of the patient despite the resistance showed by the uninvolved areas of the skin.

\section{References}

1. Kim J, Krueger JG2 (2015) The immunopathogenesis of psoriasis. Dermatol Clin 33: 13-23.

2. Gudjonsson JE, Thorarinsson AM, Sigurgeirsson B, Kristinsson KG, Valdimarsson $\mathrm{H}$ (2003) Streptococcal throat infections and exacerbation of chronic plaque psoriasis: a prospective study. Br J Dermatol 149: 530-534.

3. Naldi L, Peli L, Parazzini F, Carrel CF, Psoriasis Study Group of the Italian Group for Epidemiological Research in Dermatology (2001) Family history of psoriasis, stressful life events, and recent infectious disease are risk factors for a first episode of acute guttate psoriasis: results of a case-control study. J Am Acad Dermatol 44: 433-438.

4. Schön MP, Boehncke WH (2005) Psoriasis. N Engl J Med 352: 1899-1912.

5. Krueger JG (2002) The immunologic basis for the treatment of psoriasis with new biologic agents. J Am Acad Dermatol 46: 1-23.

6. Griffiths CE, Barker JN (2007) Pathogenesis and clinical features of psoriasis. Lancet 370: 263-271. 
7. Van de Kerkhof PC (2007) The evolution of the psoriatic lesion. Br J Dermatol 157: 4-15.

8. Körver JE, van Duijnhoven MW, Pasch MC, van Erp PE, van de Kerkhof PC (2006) Assessment of epidermal subpopulations and proliferation in healthy skin, symptomless and lesional skin of spreading psoriasis. $\mathrm{Br} \mathrm{J}$ Dermatol 155: 688-694.

9. Wrone-Smith T, Nickoloff BJ (1996) Dermal injection of immunocytes induces psoriasis. J Clin Invest 98: 1878-1887.

10. Baker BS, Swain AF, Fry L, Valdimarsson H (1984) Epidermal T lymphocytes and HLA-DR expression in psoriasis. Br J Dermatol 110: 555-564.

11. Vissers WHPM, Arndtz CHM, Muys L, Van Erp PEJ, De Jong EMG, et al. (2004) Memory effector (CD45RO+) and cytotoxic (CD8+) T cells appear early in the margin zone of spreading psoriatic lesions in contrast to cells expressing natural killer receptors, which appear late. $\mathrm{Br} J$ Dermatol 150 : 852-859.

12. Johannisson A, Festin R (1995) Phenotype transition of CD4+ T cells from CD45RA to CD45R0 is accompanied by cell activation and proliferation. Cytometry 19: 343-352

13. Komine M, Karakawa M, Takekoshi T, Sakurai N, Minatani Y, et al. (2007) Early inflammatory changes in the "perilesional skin" of psoriatic plaques: is there interaction between dendritic cells and keratinocytes? J Invest Dermato 127: 1915-1922.

14. Salem A, Nasar A, Kandil A, Farag R, El- Kasheshy K (2014) Role of vascular endothelial growth factor, surviving, and inducible nitric oxide synthtase expression in psoriasis: an immunohistochemical study. Egypt J Dermato Venereol 34: 21-26.

15. Keijsers RR, van der Velden HM, van Erp PE, de Boer-van Huizen RT, Joosten I, et al. (2013) Balance of Treg vs. T-helper cells in the transition from symptomless to lesional psoriatic skin. Br J Dermatol 168: 1294-1302.

16. Deguchi M, Aiba S, Ohtani H, Nagura H, Tagami H (2002) Comparison of the distribution and numbers of antigen-presenting cells among T-lymphocyte-mediated dermatoses: CD1a+, factor XIIla+, and CD68+ cells in eczematous dermatitis, psoriasis, lichen planus and graft-versus-host disease. Arch Dermatol Res 294: 297-302.
17. Gordon KB, Bonish BK, Patel T, Leonardi CL, Nickoloff BJ (2005) The tumour necrosis factor-alpha inhibitor adalimumab rapidly reverses the decrease in epidermal Langerhans cell density in psoriatic plaques. $\mathrm{Br} \mathrm{J}$ Dermatol 153 : 945-953.

18. Ochoa MT, Loncaric A, Krutzik SR, Becker TC, Modlin RL (2008) "Dermal dendritic cells" comprise two distinct populations: CD1+ dendritic cells and CD209+ macrophages. J Invest Dermatol 128: 2225-2231.

19. Cumberbatch M, Singh M, Dearman RJ, Young HS, Kimber I, et al. (2006) Impaired Langerhans cell migration in psoriasis. J Exp Med 203: 953-960.

20. Simonetti O, Lucarini G, Campanati A, Goteri G, Zizzi A, et al. (2009) VEGF survivin and NOS overexpression in psoriatic skin: critical role of nitric oxide synthases. J Dermatol Sci 54: 205-208.

21. Avramidis G, Krüger-Krasagakis S, Krasagakis K, Fragiadaki I, Kokolakis G, et al. (2010) The role of endothelial cell apoptosis in the effect of etanercept in psoriasis. Br J Dermatol 163: 928-934.

22. Elias PM, Arbiser J, Brown BE, Rossiter H, Man MQ, et al. (2008) Epidermal vascular endothelial growth factor production is required for permeability barrier homeostasis, dermal angiogenesis, and the development of epiderma hyperplasia: implications for the pathogenesis of psoriasis. Am J Pathol 173: 689-699.

23. Heidenreich R, Röcken M, Ghoreschi K (2009) Angiogenesis drives psoriasis pathogenesis. Int J Exp Pathol 90: 232-248.

24. Detmar M, Brown LF, Claffey KP, Yeo KT, Kocher O, et al. (1994) Overexpression of vascular permeability factor/vascular endothelial growth factor and its receptors in psoriasis. J Exp Med 180: 1141-1146.

25. Goodfield M, Hull SM, Holland D, Roberts G, Wood E, et al. (1994) Investigations of the 'active' edge of plaque psoriasis: vascular proliferation precedes changes in epidermal keratin. Br J Dermatol 131: 808-813.

26. Detmar M, Brown LF, Schön MP, Elicker BM, Velasco P, et al. (1998) Increased microvascular density and enhanced leukocyte rolling and adhesion in the skin of VEGF transgenic mice. J Invest Dermatol 111: 1-6. 